\title{
Un análisis multimodal de los elementos circunstanciales y ambientes de libros álbum que rompen estereotipos de género ${ }^{1}$
}

\author{
A multimodal study on locations \\ and inter-circumstantial relations in picture books \\ with challenge gender stereotypes
}

\author{
ARSENIO JESÚS MOYA-GUIJARROa \\ CRISTINA CAÑAMARES TORRIJOSa
}

\begin{abstract}
${ }^{a}$ Universidad de Castilla-La Mancha, Facultad de Educación de Cuenca. España. Correos electrónicos: arsenio.mguijarro@uclm.es, cristina.canamares@uclm.es
\end{abstract}

El objetivo de este artículo es identificar las relaciones inter-circunstanciales y localizaciones donde se mueven los personajes femeninos de seis libros álbum que rompen con estereotipos de género. Se analiza, para ello, si los personajes femeninos se mantienen siempre en los mismos escenarios o si, por el contrario, se introducen nuevas localizaciones en ilustraciones sucesivas y se producen variaciones contextuales que determinan el estatus personal o social de los personajes. La semiótica social de Kress y van Leewuen (2006) y de Painter, Martin y Unsworth (2013) son los modelos utilizados para llevar a cabo esta investigación. Los resultados del análisis indican que en las historias analizadas la emancipación de la mujer suele estar asociada a un contexto o localización específica. Aunque predominan las ilustraciones con el mismo grado de detalle a nivel circunstancial, en ocasiones se produce una variación en el grado de elementos circunstanciales. Entonces las protagonistas reciben una mayor prominencia, ya que el foco de atención del lector visual se centra en ellas mismas casi exclusivamente, lo que contribuye a favorecer su empoderamiento en los ambientes donde antes no se les valoraba.

Palabras claves: multimodalidad, semiótica social, localizaciones, relaciones inter-circunstanciales, libro álbum.

The aim of this article is to identify the inter-circumstantial relations and locations where the female characters of six picture books that challenge gender stereotypes evolve. To this aim, we analyzed

\footnotetext{
${ }^{1}$ Este artículo es parte del proyecto de investigación I+D, referencia FFI2017-85306-P (AMULIT: La Construcción del discurso en libros álbum que rompen estereotipos de género y el concepto de familia tradicional), financiado por el Ministerio español de Economía Industria y Competitividad /2018-2020.
} 
whether the female characters always appear in the same settings in successive illustrations or, on the contrary, whether new locations, which determine the characters' personal and social statuses, are introduced in successive illustrations. Kress and van Leewuen's (2006) and Painter, Martin and Unsworth's (2013) Social Semiotics are the approaches adopted to carry out this research. The results of the analysis show that in the six picture books women's emancipation is often associated with a specific context or location. Although illustrations with the same degree of detail at circumstantial level predominate, sometimes there is a variation in the degree of circumstantial elements. In these cases, the female characters are given greater prominence, as the reader's focus is almost exclusively on them. This contributes to their being empowered in the situations where they were hitherto undervalued.

Key words: multimodality, social semiotics, locations, inter-circumstantial relations, picture books.

\section{INTRODUCCIÓN}

El objetivo de este artículo es profundizar en el estudio del libro álbum infantil desde un enfoque lingüístico y multimodal, ampliando los análisis que sobre este género se han realizado desde puntos de vista esencialmente literarios o didácticos. Los libros álbum han sido estudiados desde perspectivas literarias y de contenido (Moebius 1986, Nodelman 1988, Lewis 2006 o Nikolajeva y Scott 2001, entre otros), psicológicas y cognitivas (Pinar 2015 o Moya-Guijarro 2019, en prensa), en base a enfoques relacionados con el análisis crítico del discurso (Fairclough 2003, Sunderland 2012), o en relación al mundo del arte (Zaparaín y González 2010). A pesar de la naturaleza multimodal del libro álbum, en estos análisis la interrelación que se establece entre texto e imágenes ha sido, en ocasiones, descuidada o, en el mejor de los casos, analizada en función de taxonomías formadas por categorías un tanto difusas. Como indica Bateman (2014), la interfaz texto-imagen se ha explorado utilizando clasificaciones excesivamente ancladas en modelos léxico-gramaticales establecidos que no son fácilmente adaptables al modo visual. Hay también investigadores como Unsworth (2006, 2014) o Martin (2008), entre otros, que han realizado análisis aislados de libros álbum desde una perspectiva multimodal, pero son escasos todavía los estudios multimodales en los que se examina una muestra de varias narrativas infantiles unidas por una temática y propósito comunicativo específico, en nuestro caso cuestionar estereotipos de género.

Ciertamente, entre las distintas temáticas que se tratan en el libro álbum está la relacionada con aspectos de género, como demuestran los estudios elaborados por Wharton (2005), Mills (2008) o Sunderland (2012), entre otros. Las investigaciones llevadas a cabo en este sentido demuestran que los personajes masculinos superan en número a los femeninos en estas narraciones infantiles, tanto en el modo lingüístico como en las ilustraciones. McCabe et al. (2011), por ejemplo, analizaron 6.618 cuentos escritos a lo largo del siglo XX desde una perspectiva psicológica y social, prestando atención a la frecuencia de aparición de los personajes masculinos y femeninos en los títulos y en el cuerpo de los cuentos. Los resultados del análisis 
revelaron que la figura masculina aparecía reflejada el doble de veces más que la femenina en el título y, a su vez, que los personajes masculinos desempeńaban un rol protagonista 1.6 veces más que los femeninos. En ningún libro de las colecciones analizadas las mujeres se representan con más frecuencia que los hombres. Estas disparidades, indican los autores, tienen implicaciones en la imagen de género que se construye el nińo: las mujeres son ignoradas o no tenidas lo suficientemente en cuenta en los libros destinados a este público infantil.

Ahora bien, también es cierto que desde la década de los 80 se han publicado cuentos feministas que ensalzan, en cierta medida, el papel de la figura femenina; seis ejemplos de ello son las historias que analizaremos en este estudio, escritos o traducidos a la lengua inglesa y protagonizados todos por niñas o mujeres que rompen con los estereotipos de género establecidos en las narrativas infantiles tradicionales: The Paper Bag Princess de Robert Musch y Michael Martchenko, Piggybook de Anthony Browne, The Princess Knight de Cornelia Funke y Kerstin Meyer, I'm a girl de Yasmeen Ismail, Arthur and Clementine de Adela Turín y Nella Bosnia y, finalmente, My Mom is a Firefighter de Lois. G. Grambling y Jane Manning.

En un intento por arrojar luz sobre las estrategias verbales y visuales que utilizan autores e ilustradores del libro álbum para fomentar un discurso de género progresista, siguiendo el enfoque de la Semiótica Social de Kress y van Leewuen (2006) y Painter et al. (2013), el objetivo de este artículo es analizar las relaciones inter-circunstanciales y ambientes donde navegan los personajes principales de libros álbum que rompen de una forma u otra con estereotipos de género anclados en la tradición popular. Estudiaremos, para ello, si los personajes femeninos de las historias seleccionadas se mantienen siempre en los mismos escenarios o si, por el contrario, se introducen nuevas localizaciones en ilustraciones sucesivas y se producen cambios de contexto (interiores o exteriores); en este caso se analizará si la introducción de nuevas localizaciones refleja posibles cambios de estatus personal o social. Averiguaremos también si estos cambios en ambientación circunstancial del modo visual tienen un reflejo en el componente verbal.

El artículo se estructura en las siguientes secciones. Tras la introducción, en la sección 2 se describe sucintamente el marco teórico en el que se sustenta esta investigación: la semiótica social de Kress y van Leewuen (1996, 2006), posteriormente readaptada para el estudio de las narrativas visuales por Painter et al. (2013) y Painter (2018). En la sección 3 se presenta el análisis de las relaciones inter-circunstanciales (Painter et al. 2013) que predominan en las historias analizadas. El artículo concluye con la sección 4 donde se exponen los resultados del estudio y se identifican las estrategias verbales y visuales que utilizan autores e ilustradores a nivel circunstancial para romper estereotipos de género en los libros álbum objeto de estudio.

\section{Semiótica SOCIal y MULtimodalidad}

El modelo de semiótica social propuesto por Kress y van Leeuwen (2006), derivado, a su vez, del modelo sistémico-funcional de Halliday (2004), servirá de base para realizar el estudio que aquí proponemos, ya que cuenta con una larga tradición en el estudio 
de textos orales y escritos y géneros relacionados con el ámbito educativo. Este modelo, inicialmente desarrollado para el estudio de imágenes de cualquier tipo, incluyendo anuncios publicitarios estáticos, noticias, caricaturas etc.; ha sido posteriormente ampliado para el estudio de cuentos infantiles por Painter et al. (2013), quienes consideran que el enfoque de Kress y van Leeuwen (2006), aunque de indudable valor, necesita una readaptación para abordar algunos aspectos de los libros álbum, esencialmente aquellos relacionados con las representaciones completas o metonímicas de los personajes en imágenes sucesivas, focalización, ambientación o, entre otros, aspectos de interrelación entre los modos verbales y visuales. Por ello, tras haber observado las opciones visuales de un total de 73 narrativas visuales publicadas en un periodo de 100 años, los lingüistas australianos desarrollan y completan los sistemas visuales ya existentes a nivel representacional, interpersonal y textual (Halliday 2004), y proponen nuevas herramientas de análisis a nivel visual y metafuncional, entre ellas, el sistema de relaciones inter-circunstanciales que describimos a continuación.

Antes, sin embargo, en un intento de ubicarlo dentro de la metafunción a la que pertenece, haremos una breve referencia al valor que Kress y van Leeuwen (2006) y Painter et al. (2013), conceden a los sistemas de significado y al carácter metafuncional de la lengua. Dentro de la sistémica funcional y de la semiótica visual, la lengua se concibe como un conjunto de sistemas de elecciones abstractas con potencial significativo, organizados desde una perspectiva metafuncional y relacionados entre sí (Halliday 2004). Una vez que una opción ha sido seleccionada dentro de un sistema en un contexto específico de comunicación, su carácter abstracto se actualiza como un ejemplo real de lengua para cumplir una función comunicativa dentro de un contexto social determinado (véase Figura 1 como ejemplo de sistema).

La semiótica social, a su vez, proporciona las herramientas necesarias para abordar las tres metafunciones básicas que la lengua desempeña: (i) la representacional o experiencial, la que nos interesa a nosotros en este artículo, que da cuenta de los recursos semióticos disponibles en una lengua para comunicar y representar nuestra experiencia de la realidad, (ii) la interactiva, que analiza los recursos para generar interacción comunicativa, y, por último, (iii) la textual, que analiza como los elementos representacionales e interactivos se combinan entre sí para crear mensajes informativamente coherentes (Halliday 2004; Kress y van Leeuwen 2006; Painter et al. 2013; Moya y Cañamares 2020).

\subsection{El sistema de relaciones circunstanciales}

La función representacional revela cómo la lengua puede expresar nuestra experiencia interna y externa de la realidad, a través de opciones significativas dentro del sistema de transitividad que implica: i. la selección de un tipo determinado de procesos (materiales, relacionales, mentales, de comportamiento, verbales y existenciales), típicamente realizados mediante verbos, ii. un número y tipo de participantes adscritos a los procesos (personas, cosas, entidades abstractas), así como los atributos o cualidades que los caracterizan e identifican y, finalmente, iii. las circunstancias de tiempo, lugar, modo etc. en las que los procesos se desarrollan, foco de atención de la investigación que se realiza en este artículo. 
De la misma forma que en la lengua escrita hay distintas opciones dentro del sistema de componentes circunstanciales (lugar, tiempo, modo, causa, compañía, etc.), en el modo visual los procesos y los participantes asociados con ellos se ubican dentro de contextos situacionales específicos, que pueden determinar de una manera u otra el estatus de los personajes que en ellos navegan. El grado de detalle otorgado a la información de carácter circunstancial puede variar mucho entre imágenes sucesivas; en otras ocasiones, sin embargo, se mantiene el mismo grado de detalle en una secuencia de imágenes (Painter et al. 2013: 78-80). En este sentido, dentro del sistema de relaciones inter-circunstanciales (véase Figura 1), Painter et al. (2013) distinguen dos opciones básicas: i. variación en el grado de detalle de información circunstancial y ii. mismo grado de detalle entre dos representaciones sucesivas.

Figura 1. Sistema de relaciones inter-circunstanciales (adaptado de Painter et al. 2013: 80)

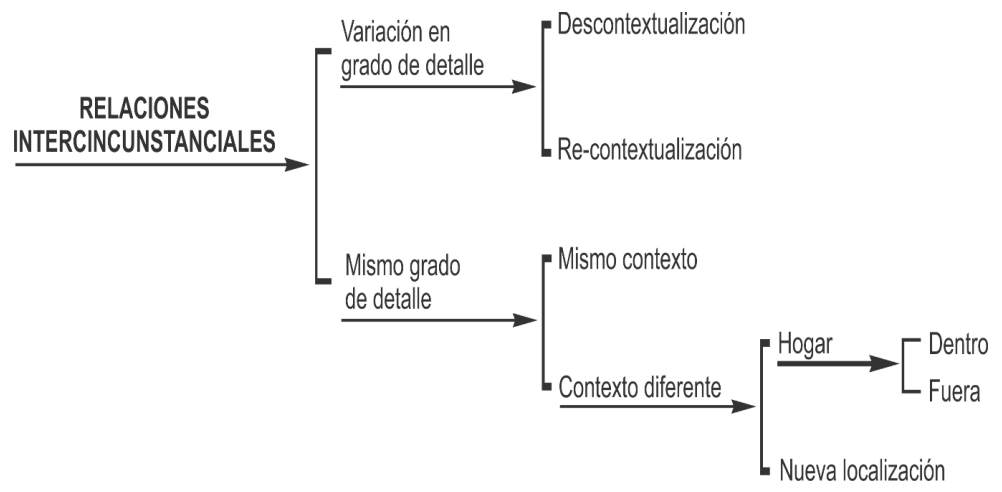

Si hay un cambio en la información circunstancial, pueden darse, a su vez, dos opciones: recontextualización y descontextualización. Si la información circunstancial se descontextualiza, es decir, se reduce en detalle en comparación a una representación previa, el personaje gana prominencia y capacidad para transmitir emociones. Si, por el contrario, la información circunstancial gana en detalle (recontextualización), aumentando con respecto a una representación previa, el participante que acaparaba previamente la atención pierde prominencia y se introduce al lector visual en una atmósfera diferente, quizás para sugerir simplemente que la historia está avanzando en el tiempo o para marcar el inicio de una nueva actividad (Painter et al. 2013: 80).

En el caso de que se mantenga el mismo grado de detalle en información circunstancial entre dos ilustraciones sucesivas, se puede, o bien mantener el mismo escenario contextual o bien cambiar la localización con respecto a la imagen previa (cambio de contexto), alternando entre ambientes interiores y exteriores dentro del hogar familiar o incluso introduciendo nuevas localizaciones (relocalización). Todas estas opciones dentro del sistema inter-circunstancial tienen una repercusión directa en la forma en que el ilustrador 
presenta a los personajes y, como comprobaremos en el análisis propiamente dicho, pueden determinar si hay una correspondencia entre los cambios de información circunstancial que pueden darse entre dos o más ilustraciones sucesivas y los cambios de estatus que pueden experimentar los personajes femeninos de las historias objeto de análisis.

\subsection{Relaciones intersemióticas a nivel circunstancial}

Ahora bien, el marco teórico que acabamos de describir quedaría incompleto si no hiciéramos referencia a las relaciones intersemióticas que se crean entre los modos verbal y visual de los libros álbum para crear significado, en nuestro caso en relación con el componente circunstancial. Para estudiar la sinergia que se crea entre los modos verbal y visual las narrativas visuales a la hora de transmitir significado, Painter et al. (2013: 134 y 143) proponen los conceptos de "actualización (commitment)," adaptado de Hood (2008), e interrelación, a través de los que podemos determinar de una forma sistemática la contribución que cada modo semiótico hace a la construcción de la historia. La aplicación del concepto de actualización permite determinar qué opciones potenciales dentro de un sistema de significado se utilizan realmente en cada uno de los modos de un ensamblaje multimodal, así como la carga semántica que transmite cada modo semiótico. Por otra parte, el término de "interrelación (coupling)" (Painter et al. 2013: 143) se emplea para comparar y determinar si los modos verbal y visual expresan una carga semántica similar o divergente cuando se actualizan significados de dos o más sistemas complementarios de forma simultánea. Esto nos permite comprobar si existen patrones repetitivos de realización de dos o más sistemas de significado en los distintos modos de un texto y su implicación en el mensaje que autor e ilustrador desean transmitir al lector. La Tabla 1 recoge los aspectos que vamos a comparar en cada modo semiótico con relación a la información de carácter circunstancial.

Tabla 1. Intersemiosis de los modos verbal y visual a nivel circunstancial

\begin{tabular}{|c|c|c|}
\hline \multicolumn{3}{|c|}{ Metafunción representacional. Información circunstancial } \\
\hline Significado potencial & Realización visual & Realización verbal \\
\hline $\begin{array}{l}\text { Información de carácter } \\
\text { circunstancial }\end{array}$ & $\begin{array}{l}\text { - Representación visual de } \\
\text { lugar, tiempo y modo, etc., } \\
\text { - Cambios y continuidades } \\
\text { en localizaciones, } \\
\text { - Localizaciones descontex- } \\
\text { tualizada/ recontextualiza- } \\
\text { da, } \\
\text { - Mismo contexto/ contexto } \\
\text { diferente, etc. } \\
\text { - Casa / Exteriores } \\
\text { - (Painter et al. 2013) }\end{array}$ & $\begin{array}{l}\text { Especificación circunstancial de: } \\
\text { - Lugar (ej: in the park), } \\
\text { - Tiempo (yesterday), } \\
\text { - Causa (for fun), } \\
\text { - Modo (carelessly), } \\
\text { - Compañía (with his father) } \\
\text { - Extensión (from Mondays to Wednessdays), } \\
\text { - Asunto (about his shorts), } \\
\text { - Contingencia (despite his friend's protest), } \\
\text { - Ángulo (according to his husband), } \\
\text { - Rol (as a head teacher) (Halliday 2004) }\end{array}$ \\
\hline
\end{tabular}




\section{ANÁlisis DE LAS RELACIONES INTER-CIRCUNSTANCIALES EN LOS MODOS VERBAL Y VISUAL}

Una vez descritos los objetivos del artículo y el marco teórico elegido para realizar el estudio que proponemos, en esta sección presentamos la muestra de álbumes ilustrados objeto de análisis, la metodología utilizada para llevar a cabo la investigación, el análisis de los componentes circunstanciales y ambientes en los modos semióticos verbales y visuales, así como la sinergia que se crea entre ellos en las narrativas visuales seleccionadas.

\subsection{Muestra de libros álbum para su análisis}

En este estudio se analizan seis historias en las que se ensalza el papel de la figura femenina. Son libros protagonizados por niñas o mujeres que de una u otra forma rompen con los estereotipos de género y empoderan la figura femenina. En su elección han primado los siguientes criterios: i. son libros relevantes/ destacados en el panorama editorial por ser considerados clásicos y/o por tener traducciones a otras lenguas, en nuestro caso al inglés; ii. son álbumes ilustrados dirigidos a jóvenes lectores que, en ocasiones, necesitan de un mediador adulto para acceder a la obra.; iii. todos están "vivos" editorialmente hablando, es decir, se editan actualmente, están disponibles y son accesibles para sus lectores en bibliotecas y librerías y, finalmente, iv. son libros considerados coeducativos, es decir, promueven la ruptura con estereotipos de género tradicionales.

Así, en The Paper Bag Princess de Robert Musch y Michael Martchenko, se retan los estereotipos establecidos sobre princesas y dragones en los cuentos tradicionales. La princesa Elizabeth será la heroína que ha de salvar al príncipe Ronald de las garras de un dragón. The Princess Knight de Cornelia Funke y Kerstin Meyer cuenta la historia de Violeta, una joven princesa que desea mostrar al mundo que puede ser tan valiente y fuerte como sus hermanos. I’m a girl, escrito e ilustrado por Yasmeen Ismail, es un álbum ilustrado protagonizado por una burrita de color violeta que continuamente es confundida con un "niño" por no ajustarse a aquellos comportamientos que se presuponen o asocian a uno y otro sexo. En My Mom is a Firefighter de Lois Grambling y Jane Manning se presenta la admiración de un niño, Billy, por su madre que es bombera. Todo gira en torno al trabajo de la figura femenina, mientras que el padre de Billy cuida del niño y realiza las labores de la casa. En Arthur and Clementine de Adela Turín y Nella Bosnia se narra la historia de una tortuga sometida al dominio de su marido hasta que ella misma decide liberarse de las cargas que este pone sobre su espalda. Por último, Piggybook, escrito e ilustrado por Anthony Browne, presenta la liberación de una madre tras vivir sometida a las labores domésticas y al comportamiento machista de sus hijos y marido.

\subsection{Metodología}

Para realizar el análisis que planteamos aplicaremos una metodología cuantitativa $y$, a su vez, cualitativa, a través de la que pretendemos identificar, cuantificar e interpretar 
los recursos que a nivel circunstancial están a disposición de los autores e ilustradores de las seis narrativas visuales objeto de análisis para cuestionar estereotipos de género. Como este estudio persigue el objetivo de analizar la información circunstancial asociada a los personajes femeninos, aplicaremos el sistema de relaciones inter-circunstanciales desarrollado dentro de la semiótica social por Painter et al. (2013) y Painter (2018) dentro de la metafunción representacional de la lengua, tanto en el modo verbal como en el visual. Verificaremos, de este modo, si la información expresada en ambos modos se repite (se duplica) o si, por el contrario, cada modo contribuye de forma distinta a la construcción del mensaje que autores e ilustradores desean transmitir, aspectos que compararemos a nivel inter-circunstancial y que han quedado esencialmente recogidas en la Figura 1 y en la Tabla 1 expuestas en las secciones 2.1 y 2.2 de este artículo.

\subsection{Información circunstancial en el componente verbal}

Como refleja la Figura 2, expuesta a continuación, los elementos circunstanciales de tiempo y lugar son los más frecuentemente utilizados en los libros álbum, seguidos de circunstanciales de modo. Los circunstanciales de compañía, causa y contingencia, sin embargo, son apenas utilizados en el modo verbal, especialmente las dos últimas tipologías. A continuación, comentamos los ejemplos más destacados encontrados en los seis libros objeto de análisis.

Figura 2. Tipología de elementos circunstanciales en el modo verbal

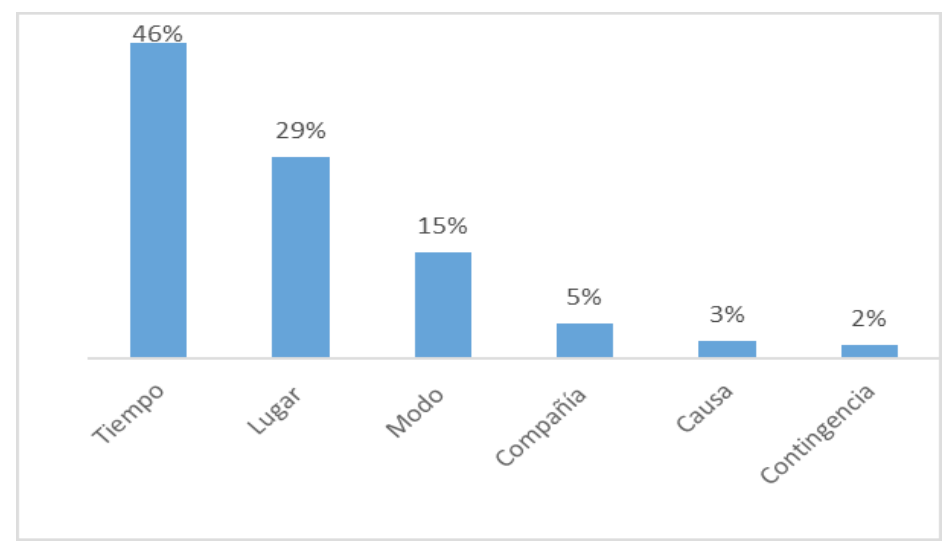

Una de las acciones fundamentales que ocurren en My Mom is a Firefighter refleja la secuenciación de un incendio que tendrá que apagar la madre del protagonista de la historia, Billy. Los circunstanciales de tiempo utilizados en el modo verbal (the next day, when the Floral Avenue rig races by, when they get to the fire, not until, after Dad and I finish eating 
and cleaning the kitchen) ordenan la secuenciación de los acontecimientos, mostrados paralelamente en la secuencia de imágenes de las dobles páginas del libro álbum, desde el comienzo del incendio cuando el camión de bomberos sale de la estación, conducido por la madre de Billy, hasta el regreso del equipo de bomberos a la misma, una vez que estos han apagado el fuego:

The next day Dad and I are making dinner when the Floral Avenue rig races by, siren screaming and red lights flashing. I run to the window. Mom's driving [...]. When they get to the fire they'll put on their air masks [...]. But their firefighter job isn't done. Not until they search the building and make sure everything has cooled down [...]. After Dad and I finish eating and cleaning the kitchen, we hear the loud HONK of the Floral Avenue rig heading back to the station (My Mom is a Firefighter).

Los circunstanciales de tiempo desempeñan también una función determinante en Piggybook. De hecho, en este libro álbum solamente se han identificado tres tipos de adjuntos circunstanciales, siendo los de tiempo los más números (21 muestras identificadas), seguidas de circunstanciales de lugar (6) y, finalmente, de compañía (1). Los adjuntos de tiempo marcan la secuenciación de los hechos en el modo verbal, desde el inicio de la historia cuando los protagonistas masculinos, el señor Piggott e hijos, muestran su comportamiento machista en todo su esplendor, hasta el abandono de la señora Piggott del hogar familiar, la transformación de los personajes masculinos en cerdos y, finalmente, la vuelta de la señora Piggott a la casa cuando Mr. Piggott y sus hijos han aprendido a respectar a la figura femenina:

[...]. After they left the house, Mrs Piggott washed all the breakfast things... made all the beds ... vacuumed all the carpets and then she went to work [...] As soon as they had eaten, Mrs Piggott washed the dishes [...] did the ironing ... and then she cooked some more [...]. One evening when the boys got home from school there was no-one to greet them. 'Where's Mum?' demanded Mr Piggott when he got home from work. [...]. The next day and the next night and the day after that Mrs Piggott was still not there [...]. Soon the house was like a pigsty [...]. (Piggybook).

Por otra parte, los circunstanciales de lugar aparecen también de forma frecuente en el modo verbal de las historias. Ahora bien, la localización espacial viene dada de una forma imprecisa y esquemática, sin apenas determinar. A su vez, los circunstanciales de lugar no aportan detalles sobre las localizaciones de los distintos ambientes donde se desarrolla la trama argumental, tan solo se limitan a mencionar los lugares interiores o exteriores donde ocurren los hechos en los que están involucrados los personajes de forma generalizada. Será la ilustración, como veremos posteriormente, la encargada de suplir esta información y localizar espacialmente el relato. Así, en The Princess Knight los circunstanciales de lugar sitúan 
la acción en el castillo del Rey Wilfred como elemento central. Al final del relato aparece una localización imprecisa, una indeterminación tomada de los cuentos populares, en los que los circunstanciales de lugar se refieren a lugares comunes e indeterminados; el modo verbal indica que la princesa se marchó a un lugar lejano, no específico, proporcionando una información esquemática y laxa sobre la localización espacial: "Then she turned her horse and rode away -far, far away. And she didn't return for a year and a day" (The Princess Knight, última doble página). De forma similar, en Piggybook los adjuntos circunstanciales de lugar en el modo verbal nos sitúan de forma imprecisa en el escenario en el que suceden los hechos principales y a sus personajes: "Mr Piggott lived with his two sons, Simon and Patrick, in a nice house with a nice garden, and a nice car in the nice garage. Inside the house was his wife" (Piggybook). En estas líneas los circunstanciales de lugar y de compañía, estos últimos con escasa presencia en el texto de los libros álbum analizados, se solapan para introducir la problemática de la historia desde el principio de la narración, las actitudes machistas de los personajes masculinos de la familia de La Cerda. El seńor Piggott vive con sus hijos, Simon y Patrick, en una casa grande y bonita que se deja ver en el fondo de la ilustración. Su esposa (sin nombre y sin identidad), sin embargo, no aparece en el exterior junto a ellos; el texto únicamente anuncia que se encuentra dentro de la casa. El hecho de que el nombre de la seńora Piggott no aparezca en el texto, solo se cita un lacónico "his wife", hace que la identidad del personaje se reduzca. Si a este hecho, añadimos que el texto afirma que la esposa está "inside the house" y que la ilustración no la representa, la relevancia del personaje en la historia se desdibuja.

Por último, aunque con una frecuencia menos notable que los anteriores, los circunstanciales de modo también se utilizan en los libros álbum para adscribir cualidades a los personajes o ayudar a definir algunas de sus conductas. Un claro ejemplo de ello lo ofrece The Paper Bag Princess en la penúltima doble página del álbum cuando la princesa libera al príncipe Ronald del dragón. Este la rechaza y le recrimina su mala apariencia, pidiéndole que no lo rescate hasta que vista como una verdadera princesa. El circunstancial de modo (like a REAL PRINCESS), incluido en un adjunto de tiempo (when you are dressed) revelan, junto a la ilustración, la excesiva preocupación del príncipe Ronald por las apariencias de su prometida, preocupación que no le permite apreciar la valentía y astucia de la princesa Elizabeth en el momento de enfrentarse al dragón que quemó su castillo y sus ropas: "You have no shoes! You are wearing a paper bag. Come back and rescue me when you are dressed like a REAL PRINCESS". (The Paper Bag Princess).

Otro de los circunstanciales de modo dignos de mención lo encontramos en la séptima doble página de I'm a Girl, un libro álbum con escasa información circunstancial en el modo verbal y en el visual, ya que centra la atención del lector en la única protagonista de la historia, una burrita que es constantemente confundida con un "chico", dado que no se ajusta a los estereotipos femeninos que se esperan de una dama: es rápida, valiente y espontánea, etc. Se pasa la historia repitiendo constantemente que es una chica. El circunstancial de modo, 'my own way' (a mi manera) anuncia la verdadera personalidad de la protagonista, siempre aceptando su realidad y sintiéndose orgullosa de sí misma: "I like 
to be spontaneous and do things my own way [...]. I'm a girl! I'm a girl! I'm a girl. There's no one else we'd rather be" (I'm a Girl).

\subsection{Relaciones inter-circunstanciales en el modo visual}

Una vez identificados los elementos circunstanciales en el modo verbal, en esta sección analizaremos los escenarios y ambientes que aparecen en las ilustraciones, centrándonos sobre todo en los cambios de carácter contextual que sufren los espacios donde se mueven los personajes, así como en la información que este modo aporta a la trama narrativa, haya sido introducida o no previamente en el modo verbal. Predominan, como se puede apreciar en la Figura 3, las ilustraciones con un mismo grado de detalle a nivel circunstancial (74\% de los casos identificados), con la utilización de contextos diferentes, pues las protagonistas de nuestras historias tienden a moverse de espacios interiores (hogar) a exteriores (fuera de palacio o del hogar). En estos últimos es precisamente donde se lleva a cabo la liberación de los personajes femeninos, cuyas circunstancias vitales los han puesto ante una carencia que tendrán que solventar, tal y como le sucede a la madre protagonista de Piggybook o a las princesas Violetta y Elizabeth en The Princess Kinght o The Paper Bag Princess, respectivamente. En otras ocasiones el reconocimiento de la figura femenina se ofrece como algo dado y merecedor y texto e ilustraciones se combinan para dar muestra de ello. Así las localizaciones de My Mom is a Firefighter (to the station) reflejan el lugar de trabajo de la madre protagonista, admirada en todo momento por su hijo, Billy y su marido. En I'm a Girl es el componente visual el que muestra los distintos ambientes, con el mismo grado de detalle prácticamente en todos ellos, donde la protagonista se muestra tal y como es, de una forma natural y espontánea; el modo verbal, sin embargo, carece de información circunstancial de lugar concreta. Veamos algunos ejemplos significativos con más detalle.

Figura 3. Grado de detalle en la información circunstancial.

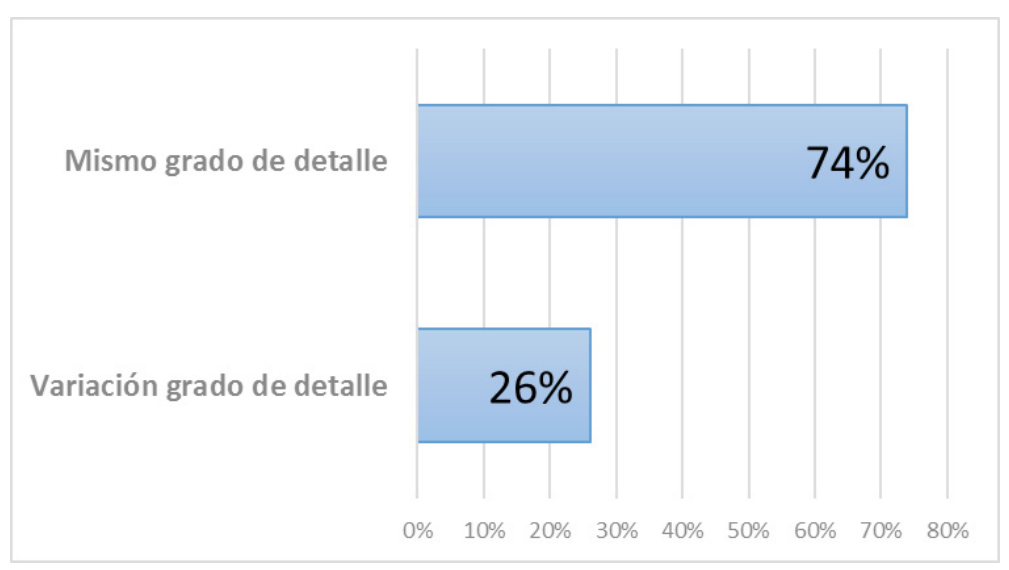


En The Princess Knight las ilustraciones presentan el mismo grado de detalle a lo largo del relato, aunque hay varios cambios contextuales o de localización desde las primeras imágenes (en el interior del castillo) a las del final, ubicadas en el exterior del castillo por motivos que exige la trama argumental: las justas para combatir por la mano de la princesa Violetta se celebran en los espacios exteriores del castillo, así como las prácticas que la princesa lleva a cabo en el bosque (nueva localización) para dominar las destrezas de la lucha. También se han contabilizado tres casos de variación en grado de detalle en información circunstancial, a los que haremos referencia en breve. Todas las ilustraciones están inspiradas en la tapicería de Bayeux. De ahí que predomine la utilización de una sucesión de imágenes con motivos medievales en las dobles páginas del relato. En esa sucesión de imágenes se muestran varias acciones encadenadas de lectura visual que indican una sucesión cronológica de acontecimientos (Moya-Guijarro 2020) y que, por lo tanto, ralentizan e incluso detienen la lectura. Este recurso se utiliza en este álbum ilustrado esencialmente para conseguir un efecto reiterativo de hechos destacados que el ilustrador desea dejar claros al joven lector. En los ambientes exteriores (bosque) se refleja, por ejemplo, como el caballero "Sir No-Name", en realidad la Princesa Elizabeth escondida bajo su armadura, aparece en tres ocasiones en una misma ilustración para aportar un sumario de caballeros a los que derrota y, así, ganar el respeto de su padre y hermanos.

Dignas de mención son las tres variaciones en grado de detalle otorgadas a la información circunstancial en las dobles páginas décimo séptima y última. A fin de mostrar el contraste en ambientación entre dos ilustraciones sucesivas, se reproduce la décimo séptima ilustración en la Figura 4, así como la ilustración previa, la décimo sexta, donde el rey llama a la princesa para comunicarle que el premio del torneo convocado por su décimo

Figura 4. Variación en el grado de detalle. Descontextualización. Ilustraciones tomadas de The Princess Knight (2003). (C) Kerstin Meyer.

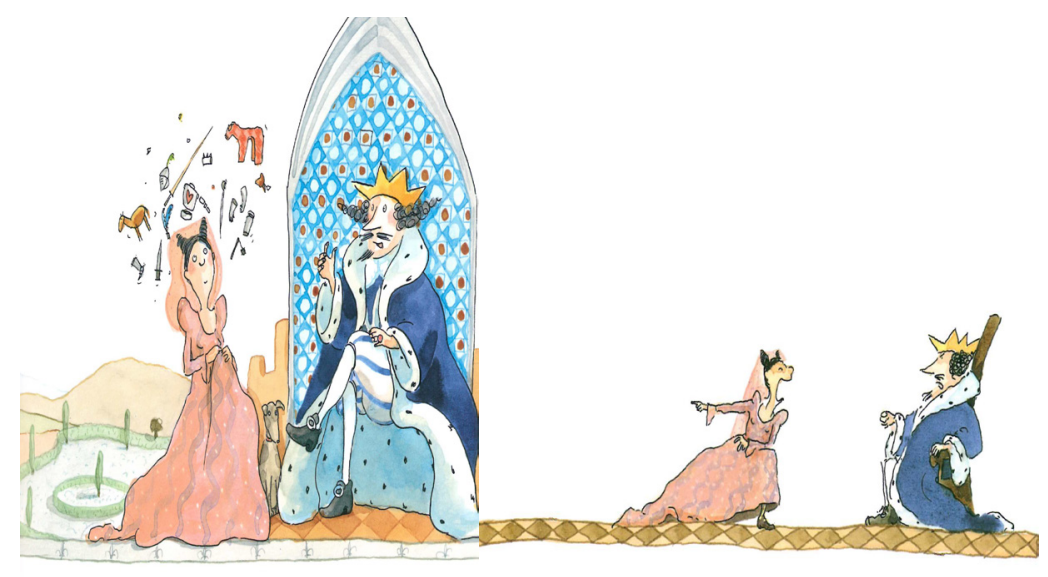


sexto cumpleaños para el caballero ganador de las justas será su mano en matrimonio. Cuando Violetta es consciente de la decisión real entra en cólera, hecho que se refleja en una ilustración carente de contexto ambiental, donde el foco de atención es la discusión de dos personajes reales, padre e hija. Este hecho es relevante, ya que Violetta, aunque mujer, se niega aceptar el destino que para ella tiene forjado el rey. De forma similar, en la última doble página se aprecian dos ilustraciones descontextualizadas, que también muestran dos momentos importantes de la historia. En la parte superior de la página Violetta se despide de su padre antes de partir del reino, al que no volverá tras un año y un día. En la parte inferior de la ilustración Violetta aparece ya casada con el hijo del jardinero, rompiendo las normas que la sociedad del momento imponía a las princesas reales.

My Mom is a Firefighter responde igualmente al patrón de mismo grado de detalle en la información circunstancial de sus ilustraciones, utilizando en ocasiones contextos diferentes que varían entre los dos hogares del niño protagonista: su casa y la estación de bomberos donde trabaja su madre. También aparecen nuevas localizaciones como el edificio donde se produce el fuego y la escuela. Todas estas localizaciones se crean con la ayuda del color. Se utilizan los tonos anaranjados y rojizos para dar forma a los ambientes donde se mueve la madre del protagonista con su equipo de bomberos, en los que predomina la acción. En la casa de Billy y su familia, sin embargo, abundan las tonalidades amarillas y azuladas que transmiten tranquilidad y paz. Todo se combina para destacar la admiración del nińo por la figura materna, que acapara el protagonismo de la historia. En la Figura 5 reproducimos la novena doble página del libro álbum. En ella se aprecian dos ambientes diferentes: el lugar del fuego, representado por los bomberos cargando sus equipos en el camión una vez finalizado el incendio y la casa de Billy. El tono azulado del hogar familiar contrasta con los tonos rojizos del lugar del incendio. Llama especialmente la atención la

Figura 5. El coche de bomberos volviendo del incendio.

Ilustraciones tomadas de My Mom is a Firefighter (2007). (C) Jane Manning.

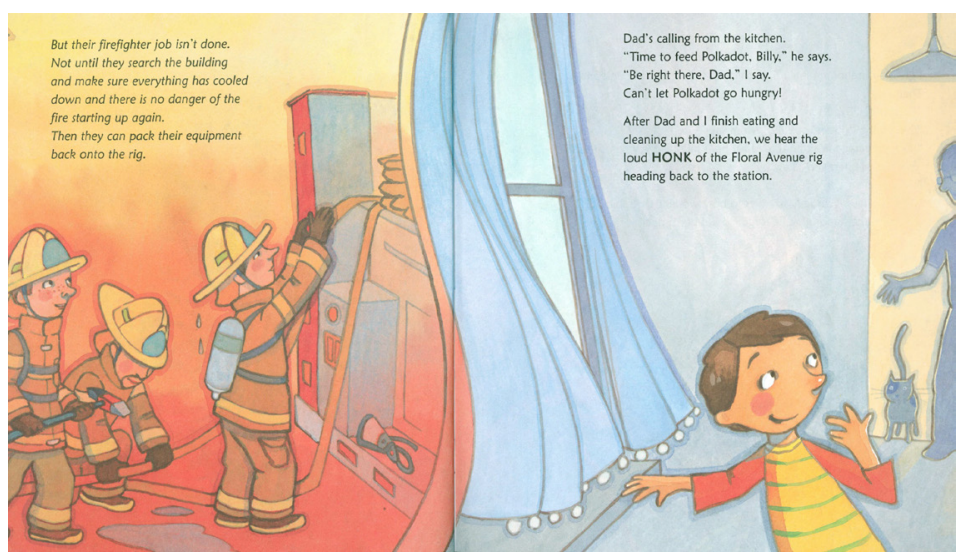


escasa prominencia que se le otorga al padre del nińo protagonista en esta ilustración, quien, representado metonímicamente, su silueta por el todo (Painter et al. 2013; Moya-Guijarro 2019, en prensa), contempla desde la cocina a Billy. La ausencia de color y forma en su representación, junto a su ubicación en el fondo de la composición, quitan protagonismo al personaje masculino del cuento, especialmente si lo comparamos con las representaciones de Billy y su madre, verdadera heroína del cuento.

Aunque sigue la tónica predominante en los seis libros álbum analizados (mismo grado de detalle a nivel circunstancial en ilustraciones sucesivas), Arthur and Clementine ofrece ejemplos de descontextualización y recontextualización dignos de mención. Las variaciones en grado de detalle a nivel circunstancial atañen a las localizaciones donde se mueve Clementine y reflejan su falta de libertad y estatus, constantemente sometida a las decisiones machistas de su marido. Así, en la octava doble página, en la parte derecha, apreciamos a Clementine sobrecargada portando sobre su caparazón un tocadiscos, un jarrón, un reloj, un cuadro, varios libros y una lámpara, todo sobre un fondo blanco, carente del color verdoso y detalles vegetales que suele predominar en la mayoría de las ilustraciones del libro. Carente de información contextual en la doble página décimo cuarta el lector visualiza la perplejidad del personaje masculino cuando llega a casa y descubre que su esposa ha abandonado el hogar (véase Figura 6). Arthur mira asombrado el caparazón ya vacío de Clementine en un fondo blanco sin contextualización alguna. De Clementine solo queda su caparazón vacío, cargado de infinidad de objetos; no se pueden visualizar todos ellos, dado que el volumen sobrepasa los límites de la ilustración. El texto complementa esta información reiterando lo que el modo visual ya muestra, el abandono de Clementine; a su vez añade los sentimientos de Arthur: "He was surprised, angry and hurt."

Figura 6. Arthur contempla el caparazón vacío de Clementine. Ilustraciones tomadas de Arthur and Clementine (1976) (C) Nella Bosnia.

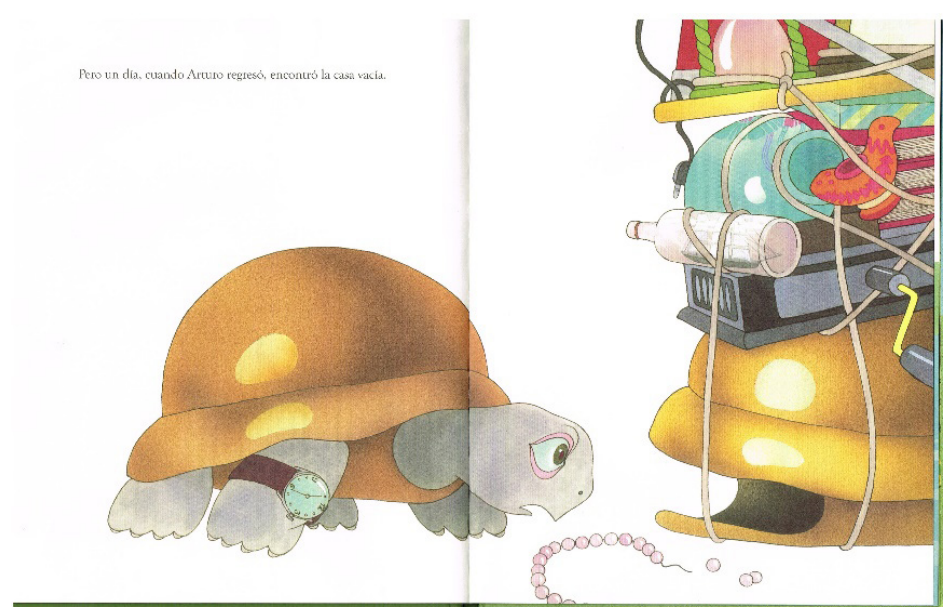


Piggybook mantiene la misma tónica que los libros analizados hasta ahora, es decir, el mismo grado de detalle en ilustraciones sucesivas sigue predominando en la narración (15 casos contabilizados). Sin embargo, es el libro álbum en el que más muestras de variaciones en el grado de detalle otorgado a la información circunstancial se han contabilizado (14). Esto se debe principalmente a que Browne utiliza once descontextualizaciones y tres recontextualizaciones para enfatizar la diferencia de estatus entre los personajes masculinos y la madre protagonista. El primer cambio en la variación de detalle en la información contextual, con descontextualización o reducción de detalles circunstanciales con respecto a una representación previa, se encuentra en la tercera doble página. Nos referimos a los cuatro cuadrantes que muestran a la señora Piggott realizando las tareas de la casa (fregando los platos del desayuno, haciendo las camas, pasando la aspiradora) y caminando hacia el trabajo en la tercera doble página del libro álbum. A diferencia de las ilustraciones previas donde aparecían los personajes masculinos de la casa, la información ambiental se difumina en estos cuatro cuadrantes, así como el personaje femenino, representado más bien por su silueta y sin unos rasgos faciales claros y específicos. El hecho de que la señora Piggott no muestre un rostro definido y que los ambientes donde se encuentra estén trazados en colores pastel y un tanto difuminados ayuda a reflejar el bajo estatus y la falta de consideración que en la casa se le profesa a la figura materna. Otros cuatro cuadrantes similares se encuentran en la parte derecha de la quinta doble página, donde la señora Piggott continúa haciendo otras tareas de la casa (fregando plantos, planchando, etc.), también en un ambiente difuminado y sin apenas detalles.

Cuando se representa a los personajes masculinos, como ocurre, por ejemplo, en la siguiente doble página, la sexta, sentados en los sillones del salón mientras ven el televisor, los ambientes se recontextualizan, ganando tanto en detalles como en colorido. Se aprecian los tulipanes del papel que cubre las paredes, la decoración de los sofás, adornos sobre el televisor, etc. Se produce, por tanto, un cambio de espacios en función del estatus de los personajes: la mujer tiende a situarse en la cocina y habitaciones (atendiendo sus labores domésticas y nunca descansando) inmersa en un halo amarillento y sofocante; el padre y los niños en las estancias nobles de la casa (pasan del exterior al salón), donde predominan colores más vivos. Todo ello contribuye a dar estatus y poder al señor Piggott e hijos dentro del hogar familiar. Véase el contraste al que hacemos alusión en la Figura 6 donde se expone uno de los cuadrantes de la tercera doble página donde el personaje femenino realiza tareas de la casa y, por otro lado, el salón familiar donde descansan el señor Piggott y sus hijos mientras ven la televisión. 
Figura 7. Contraste de ambientes: Sra Piggott en cocina / Sr. Piggott e hijos en salón. Ilustraciones tomadas de Piggybook (1988). (c) Anthony Browne.

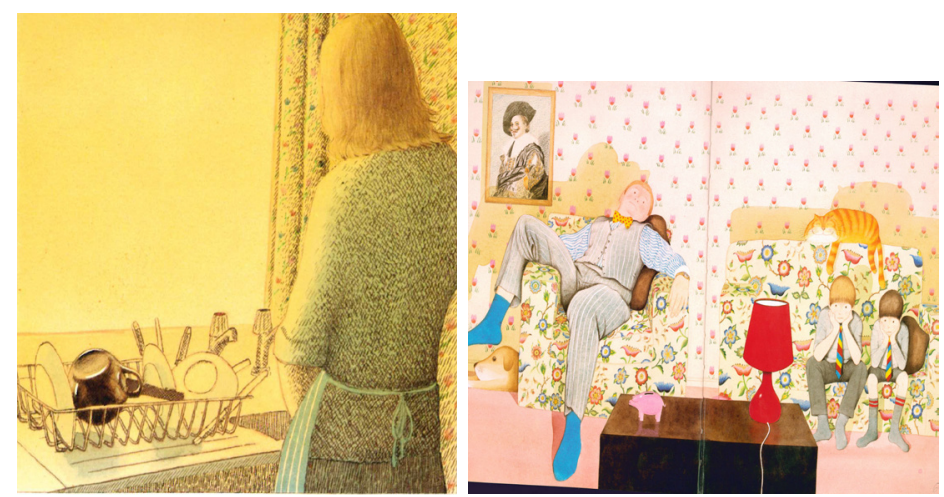

La descontextualización en el grado de detalle de la información circunstancial se hace del todo evidente en las últimas ilustraciones de Piggybook. Una vez que la madre regresa a la casa tras el abandono del hogar, en la parte derecha de la décimo segunda doble página encontramos a los personajes masculinos arrodillados ante la madre y mostrando su arrepentimiento por su comportamiento machista. En esta ilustración los detalles circunstanciales desaparecen por completo, produciéndose una descontextualización total que centra el foco del receptor del libro álbum en el señor Piggott y sus hijos y en su deseo de ser perdonados por la madre. Nótese que esta ilustración es una proyección de la imagen previa, donde la señora Piggott, de pie y sujetando un maletín en la mano como muestra de su nuevo poder, los contempla arrodillados a sus pies.

\subsection{Interrelación texto-imagen a nivel inter-circunstancial}

En línea con los objetivos planteados en la introducción, en esta sección pretendemos averiguar si hay o no diferencias significativas entre la información de carácter circunstancial que reflejan a nivel representacional los modos verbal y visual para construir un ambiente que favorezca un mensaje progresista de género en torno a la figura femenina. Llama la atención, en primer lugar, el hecho de que los circunstanciales de tiempo del modo verbal tienen generalmente un reflejo impreciso en el componente visual. Evidentemente las ilustraciones revelan la sucesión y secuenciación de acontecimientos desde la página inicial a la final siguiendo un orden temporal. Ahora bien, las concreciones temporales (the next day, when the Floral avenue rig races by, when he came home from his very important job, etc.) las incluye el modo verbal casi exclusivamente. Estos circunstanciales temporales marcan la secuencia narrativa y la sucesión de los hechos en los que están involucrados los personajes principales de forma más precisa (véase sección 3.3 donde se ofrecen varios ejemplos sobre ello). Parece existir, por tanto, una complementariedad a nivel circunstancial 
entre los modos verbal y visual de los cuentos a la hora de señalar el desarrollo cronológico temporal. Las ilustraciones invitan a detenerse, a mirar y, de alguna forma, ralentizan el ritmo de la narración; el texto, sin embargo, invita al lector a seguir leyendo, al tiempo que ofrece información de carácter temporal más concreta y específica.

A diferencia de los circunstanciales de tiempo, los de modo no tienen ningún reflejo en el componente visual, que se limita a mostrar los personajes, los procesos en los que estos están involucrados y los lugares donde se desarrollan los acontecimientos, sin indicar el modo en que los participantes realizan sus acciones. El modo en que la princesa Violeta practica las destrezas de la justa no es perceptible en las ilustraciones, el lector tiene que apoyarse en el texto para descubrir que la princesa entrenaba cuidadosamente y con sigilo, no duramente como lo hacían sus hermanos los príncipes: "Violetta practised them in her own way, without shouting and without using her spurs [...]. She was very quiet about it: as quiet as the night itself" (The Princess Knight, sexta doble página).

Por el contrario, los circunstanciales de lugar, imprecisos e indeterminados en el componente verbal, se actualizan y se determinan en las ilustraciones. En ellas el ilustrador muestra a través de sus trazos y dibujos los ambientes específicos donde los personajes se mueven. Recordemos como en The Princess Night todas los circunstanciales de lugar hacían referencia al castillo, un castillo indeterminado, donde habitan el rey Wilfred, sus tres hijos y la princesa Violetta. Serán las ilustraciones, desde la mismísima contraportada, las que muestren cómo es el castillo en realidad, así como las distintas dependencias del mismo, desde el dormitorio de la Reina fallecida tras el nacimiento de la princesa Violetta hasta el trono real. Parece evidente, por tanto, que texto e imagen se complementan a la hora de transmitir información de carácter circunstancial en los seis libros álbum objeto de análisis, ya sea esta de lugar, tiempo o modo.

A diferencia del modo verbal, las ilustraciones ofrecen relaciones circunstanciales de lugar, bien con variación, bien con el mismo grado de detalle contextual. Si se muestra el mismo grado de detalle en información circunstancial de lugar el ilustrador puede reproducir el mismo contexto o escenario entre varias ilustraciones sucesivas ( 43 casos encontrados), pero también puede ofrecer contextos diferentes, bien dentro del hogar (14 muestras), fuera de este (8 casos localizados), o también en nuevas localizaciones ( 14 casos). El entrenamiento de la princesa Violetta para acabar superando a sus hermanos en el arte de las justas y controlar las riendas de su destino en The Princess Knight, tiene lugar en localizaciones distintas (palacio, bosque, exteriores de palacio), localizaciones que suelen ofrecer un grado de detalle similar y que, aunque a veces se mencionen en el modo verbal, solamente se concretan y se especifican en el modo visual. En I’m a girl también se muestran distintos contextos con prácticamente el mismo grado de detalle (piscina, biblioteca, parque, calle, etc.) que no tienen un reflejo en el componente verbal. De esta forma se enfatiza la naturaleza activa de la protagonista, lo que hace que muchos de los personajes que se encuentran con ella la confundan con un chico. En My Mom is a Firefighter la madre suele aparecer en contextos profesionales sin grandes variaciones de detalle (estación de bomberos, edificios con fuego, escuela) para mostrar al joven lector que la mujer puede desempeñar tareas tradicionalmente asignadas al hombre. 
Por el contrario, su marido se ubica esencialmente en el entorno familiar, realizando las tareas del hogar. Estas localizaciones se actualizan y especifican sobre todo en el modo visual; en ocasiones se hace referencia a ellas en el modo verbal, pero, como se ha indicado anteriormente, de una forma poco concreta e inespecífica. A su vez, es la imagen la encargada de mostrar la transformación que sufre el hogar de la familia Piggott en Piggybook cuando este se convierte en una auténtica pocilga, cambios progresivos que el modo verbal silencia.

Aunque su frecuencia es menor, el 26\% de los casos identificados (véase Figura 3, expuesta previamente), existen ilustraciones en las que predomina una variación en grado de detalle otorgado a la información circunstancial de lugar (véase Tabla 2. En estos casos se puede producir bien una descontextualización o reducción en detalle en comparación a una representación previa, otorgando más prominencia al personaje ( $74 \%$ de los casos contabilizados), o bien una recontextualización (26\%), siempre y cuando la información circunstancial gane en detalle; se introduce entonces al lector en atmósferas diferentes. Estas variaciones en información circunstancial entre ilustraciones sucesivas dan lugar a implicaciones de carácter anti-sexista y son relevantes para analizar el estatus otorgado a los personajes a lo largo de la trama, sus carencias y la forma de superarlas. Así, en Arthur and Clementine las ilustraciones con descontextualización nos muestran sobre todo a la protagonista femenina portando los tesoros que Arthur, su marido, le compra para templar sus ganas de vivir el mundo por ella misma. En estos casos aparece portando sobre su caparazón cantidad de objetos (tocadiscos, cuadros, pinturas, lámparas, etc.) en un fondo blanco sin elemento circunstancial alguno. Toda la atención del lector visual se dirige mediante esta estrategia a la protagonista y a la carga de elementos que debe soportar sobre su caparazón, convertido en un auténtico rascacielos que la mantiene prácticamente inmóvil mientras su marido se mueve libremente por el mundo.

Tabla 2. Relaciones inter-circunstanciales en el modo visual

\begin{tabular}{|l|c|c|c|c|}
\hline \multirow{5}{*}{ OPCIONES } & \multicolumn{5}{|c|}{ Variación grado de detalle } & Mismo grado de detalle \\
\cline { 2 - 5 } & $\begin{array}{c}\text { Valores } \\
\text { absolutos }\end{array}$ & $\begin{array}{c}\text { Valores } \\
\text { relativos }\end{array}$ & $\begin{array}{c}\text { Valores } \\
\text { absolutos }\end{array}$ & $\begin{array}{c}\text { Valores } \\
\text { relativos }\end{array}$ \\
\hline Descontextualización & 23 & $74 \%$ & - & - \\
\hline Re-contextualización & 8 & $26 \%$ & - & - \\
\hline Mismo contexto & - & - & 52 & $59 \%$ \\
\hline Contexto diferente (Hogar: Dentro) & - & - & 14 & $16 \%$ \\
\hline Contexto diferente (Hogar: Fuera) & - & - & 8 & $9 \%$ \\
\hline Contexto diferente (Nuevalocalización) & - & - & 14 & $16 \%$ \\
\hline TOTAL & 31 & $100 \%$ & 88 & $100 \%$ \\
\hline
\end{tabular}




\section{CONCLUSIONES Y DISCUSIÓN}

Tras analizar la información circunstancial de los modos verbal y visual de los libros álbum objeto de estudio, podemos concluir que existe una sinergia entre texto e imagen para introducir elementos circunstanciales y ambientes, a través de la cual se crean significados complementarios que, de alguna manera, ayudan a crear un mensaje progresista a favor de la liberación y respeto a la figura femenina. Ambos modos cooperan entre sí de forma que un código incrementa y complementa al otro (Unsworth 2006: 63). En el modo verbal las opciones del sistema de relaciones circunstanciales que se actualizan en los libros álbum objeto de estudio son esencialmente los circunstanciales de lugar, tiempo y modo. Los de modo son elementos exclusivos del texto. Los de tiempo se muestran tanto en el modo verbal como en el visual, aunque las concreciones temporales se realizan esencialmente en el texto. Los complementos de lugar, sin embargo, aunque también referidos en el modo verbal de una forma un tanto indeterminada, se hacen específicos y se concretan en las ilustraciones. En estas se muestran ambientes, generalmente con el mismo grado de detalle, pero en contextos diferentes que hacen avanzar a las figuras protagonistas desde el interior de sus respectivos hogares hasta el exterior, donde se produce la liberación del personaje femenino. Ejemplos de esto son Elizabeth en The Paper Bag Princess, Violetta en The Princess Knight, la señora Piggott en Piggybook y Clementine en Arthur and Clementine.

Son historias en las que las protagonistas femeninas se enfrentan a situaciones extraordinarias en las que tienen que abandonar escenarios preexistentes, generalmente interiores y un tanto angustiosos (Moya y Cańamares 2020), para enfrentarse a su destino o a una situación extraordinaria cuya batalla se suele librar en nuevas localizaciones, generalmente exteriores, que las conducen a un cambio de estatus personal y social. En esta lucha por sus derechos las heroínas se liberan de elementos pretendidamente femeninos (belleza, cuidado personal, delicadeza) y se revisten de recursos supuestamente masculinos (abandono del hogar, fuerza física, supremacía de la inteligencia). Dichos cambios en la ambientación circunstancial se insinúan en el texto y se realizan de una forma más profunda en las ilustraciones. Otras heroínas, como la madre de Billy en My Mom is a Firefighter, cuentan ya desde el principio con el respecto de su familia y sus acciones se desarrollan en ambientes exteriores y profesionales, donde muestran sus habilidades. $\mathrm{O}$ simplemente, están orgullosas de su personalidad y su forma de ser, y la muestran en los ambientes fuera del hogar donde actúan a su manera, siguiendo sus impulsos. La protagonista femenina de I'm a Girl es prueba de ello.

En otras ocasiones, con menor frecuencia, se produce una variación en el grado de elementos circunstanciales que se muestran en la ilustración, con descontextualización o disminución en la muestra de elementos circunstanciales. Las protagonistas femeninas, entonces, reciben una mayor prominencia, ya que el foco de atención del lector visual se centra en ellas mismas casi exclusivamente. Ello contribuye a favorecer su empoderamiento y respecto en el entorno donde antes no se les valoraba. La princesa Violetta en The Princess Knight, por ejemplo, se muestra sin detalles contextuales con respecto a ilustraciones previas 
en la última página simple del libro, cuando tras vencer a todos los caballeros del reino en un torneo de justas decide marcharse de palacio y posteriormente casarse con el hijo del jardinero, rompiendo con el destino que su padre, el Rey, había trazado para ella.

Con o sin variación en grado de detalle, lo cierto es que en las historias analizadas la emancipación de la mujer y su empoderamiento suele deberse a un hecho extraordinario y está asociado a un contexto o localización específica: un dragón asola el palacio donde vivía la princesa Elizabeth en The Paper Bag Princess; un padre educa a su hija como si fuera un varón en The Princess Knight, las situaciones alineadoras en el hogar familiar de la señora Piggott y de Clementine en Piggybook y Arthur and Clementine, respectivamente, la apariencia y comportamiento de un personaje que sobrepasa lo que la sociedad considera "normalidad" en los ambientes interiores y exteriores de I'm a Girl, así como los ambientes profesionales donde se mueve la madre bombera de Billy en My Mom is a Firefighter. En los casos en los que las protagonistas tienen que vencer situaciones extremas o alineadoras no se restituye el orden que existía al principio, sino que siempre surge una nueva situación que generalmente va asociada con la liberación de las protagonistas y con un cambio o variación contextual.

Los resultados de este análisis ponen de manifiesto la carga comunicativa de los elementos circunstanciales y ambientes en los libros álbum en el modo visual. Preparemos, pues, a los jóvenes lectores, a captar los detalles contextuales que ofrecen las narrativas visuales. Vivimos en una sociedad eminentemente tecnológica y visual, donde el significado no se crea exclusivamente a través de la palabra escrita, sino mediante la combinación de distintos modos semióticos. El visual, sin duda, es uno de ellos. A través del libro álbum se puede introducir al joven lector en la lectura de imágenes para que progresivamente sea capaz de captar los significados que éstas portan en cualquier ensamblaje multimodal creado para la sociedad del siglo XXI.

\section{OBRas CITADAS}

Bateman, John. 2014. Text and Image: A Critical Introduction to the Visual/Verbal Divide. Londres y Nueva York: Routledge.

Fairclough, Norman. 2003. Analysing Discourse: Text Analysis for Social Research. Londres: Routledge.

Halliday, MAK. 2004. Introduction to Functional Grammar. $3^{a}$ Edición. Londres: Arnold.

Hood, S. 2008. "Summary writing in academic contexts: implicating meaning in processes of change". Linguistics and Education, 19: 351-365.

Kress, Gunther y Theo van Leeuwen. (2006 [1996]). Reading Images. The Grammar of Visual Design. Londres: Routledge.

Lewis, David. (2006 [2001]). Reading Contemporary Picture Books. Picturing Text. Londres: Routledge. 
Martin, Jim. 2008. "Intermodal Reconciliation: Men in Arms". New Literacies and the English Curriculum: Multimodal Perspectives. Len Unsworth (ed.). Londres: Continuum. 112- 148 .

McCabe, Janice, Emily Fairchild, Liz Grauerholz, Benice Pescosolido, y Daniel Tope. 2011. "Gender in Twentieth Century Children's Books: Patterns of Disparity in Titles and Central Characters". Gender and Society 25.2: 197-226.

Mills, Sara. 2008. Language and Sexism. Cambridge: Cambridge University Press.

Moebius, William. 1986. "Introduction to Picture Books Codes". Word and Image 2: 141-158.

Moya-Guijarro A. Jesús. 2019. “Textual functions of metonymies in Anthony Browne’s picture books: A multimodal approach”. Text \& Talk, 39.3: 389-413.

Moya-Guijarro, A. Jesús. En prensa. "The Representation of Male Characters in Three Challenging Picture Books. A Multimodal Study.” Aceptado para su publicación en Sintagma. Revista de Lingüística.

Moya-Guijarro, A. Jesús y Cristina Cañamares. 2020. Libros álbum que desafían los estereotipos de género y el concepto de familia tradicional. Análisis semiótico y multimodal. Cuenca: Arcadia.

Nikolajeva, Maria y Carole Scott. 2001. How Picturebooks Work. Nueva York: Garland Publishing.

Nodelman, Perry. 1988. Words about Pictures: The Narrative Art of Children's Picture books. Atenas: The University of Georgia Press.

Painter, Clare, Jim Martin, y Len Unsworth. 2013. Reading Visual Narratives. Image Analysis of Children's Picture Books. Sheffield: Equinox.

Painter, Clare. 2018. "Multimodal Analysis of Picturebooks". The Routledge Companion to Picturebooks. Bettina Kümmerling-Meibauer (ed.). Londres: Routledge.

Pinar, Ma Jesús (ed.). 2015. Multimodality and Cognitive Linguistics. Benjamins Current Topics. Amsterdam: John Benjamins.

Sunderland, Jane. 2012. Language, Gender and Children's Fiction. Londres: Continuum. Unsworth, Len. 2006. “Towards a Metalanguage for Multiliteracies Education: Describing the Meaning-Making Resources of Language-Image Interaction”. English Teaching, Practice and Critique 5.1: 55-76. . 2014. "The Image/Language Interface in Picture Books as Animated Films: A Focus for New Narrative Interpretation and Composition Pedagogies." English Teaching and New Literacies Pedagogy: Interpreting and Authoring Digital Multimedia Narratives. Len Unsworth \& Angela Thomas (eds.). Nueva York: Perter Lang. 105-122.

Wharton, Sue. 2005. "Invisible Females, Incapable Males: Gender Construction in a Children's Reading Scheme". Language and Education 3: 238-251.

Zaparaín Fernando y Luis Daniel González. 2010. Cruce de caminos. Álbumes ilustrados: construcción y lectura. Cuenca y Valladolid: Universidad de Castilla-La Mancha y Universidad de Valladolid. 
ESTUDIOS FILOLÓGICOS

\section{Libros álbum analizados}

Browne, Anthony. 1988. Piggybook. Londres: Walker Books.

Funke, Cornelia y Meyer, Kerstin. 2003. The Princess Knight. Somerset: The Chicken House.

Grambling, Lois y Jane Manning. 2007. My Mom is a Firefighter. Nueva York: HapperCollins.

Ismail, Yasmee. 2015. I'm a girl. Londres: Bloomsbury Publishing.

Munsch, Robert y Martchenko, Michael. 2015 [1980]. The Paper Bag Princess. Toronto: Annick Press.

Turin, Adela y Nella Bosnia. 1976. Arthur and Clementine. Londres: Writers and Readers Publishing Cooperative. 